\title{
Tribological Characterization of Hybrid Metal Matrix Composites Processed by Powder Metallurgy
}

\author{
M. Megahed ${ }^{1}$ M. A. Attia ${ }^{1}$ M. Abdelhameed ${ }^{1}$ A. G. El-Shafei ${ }^{1}$
}

Received: 8 December 2016/Revised: 5 February 2017/Published online: 15 March 2017

(C) The Chinese Society for Metals and Springer-Verlag Berlin Heidelberg 2017

\begin{abstract}
Aluminum (Al)-based aluminum oxide $\left(\mathrm{Al}_{2} \mathrm{O}_{3}\right)$ and silicon carbide $(\mathrm{SiC})$ particles hybrid metal matrix composites were processed by powder metallurgy technique, followed by sintering at $500{ }^{\circ} \mathrm{C}$ and then hot extrusion. The tribological properties of these composites with different weight fractions of $\mathrm{Al}_{2} \mathrm{O}_{3}$ and $\mathrm{SiC}$ were investigated; extrusion process significantly reduces the extent of porosity after cold compaction and sintering processes. Hybridization of the two reinforcements improved hardness and wear resistance of the composites. With an increase in SiC content, hardness was increased and consequently the wear resistance was enhanced also. Scanning electron microscopy observations show a better interfacial bond between matrix and reinforcements and a better distribution of the reinforcements.
\end{abstract}

KEY WORDS: Hybrid metal matrix composite; Powder metallurgy; Abrasive wear; Hardness; Porosity

\section{Introduction}

Aluminum has a combination of low cost, lightweight, resistance against environmental conditions and good mechanical properties. These properties make it convenient for use as a matrix material in metal matrix composites (MMCs) [1]. Aluminum matrix composites have been used in several applications as in automotive, aerospace, military and electronic industries because of its high toughness, low density and high corrosion resistance [2]. As compared to pure materials, MMCs exhibit lower wear rates due to protection of contact surfaces by hard reinforcements [3]. In the form of particles or fibers, $\mathrm{SiC}$ is considered as both structural and functional material because of its good electrical and thermal conductivity, high mechanical

Available online at http://link.springer.com/journal/40195.

M. Megahed

monawafa6@gmail.com

1 Department of Mechanical Design and Production Engineering, Faculty of Engineering, Zagazig University, P.O. Box 44519, Zagazig, Egypt strength, chemical stability and low friction properties [4]. Furthermore, silicon carbide is chemically compatible with aluminum forming a good bond with the matrix [5]. Alumina is the most common ceramic reinforcement after $\mathrm{SiC}$ reinforcement as it has higher thermal stability compared to $\mathrm{SiC}$, and thus it does not react with metal matrix at elevated temperatures and does not make brittle phases [6]. Aluminum reinforced by silicon carbide and alumina particulate is the most common aluminum MMCs.

Hybrid metal matrix composites are engineering materials reinforced by a combination of two or more different types of reinforcement to have the advantages of all of them [7]. Hybrid metal matrix composites are attractive materials for mechanical, multifunctional, medical, energy and industrial applications. Hybrid MMCs developed a second generation of composite materials. The importance of hybrid materials is due to combining different shapes, types and sizes of fillers, to form one constituent with lower weight and cost [8]. These hybrid composites, with good dispersion of the particles in the matrix [9], have improved properties such as strength, elastic modulus, coefficient of thermal expansion and wear resistance in comparison with pure aluminum. 
Wear is an essential aspect being considered during designing of these components to give better performance in any tribological applications [10]. A main disadvantage of pure aluminum is its low wear resistance. Addition of ceramic particles to aluminum matrix can improve the strength, hardness, corrosion and wear resistances of the composites [2]. Ceramics have outstanding mechanical properties such as oxidation, wear and corrosion resistances [11]. An enhancement of the tribological properties of aluminum MMCs has been successfully achieved by incorporating ceramic particles, such as silicon carbide, boron carbide, aluminum oxide and titanium carbide [9].

Several techniques have been used to manufacture MMCs including powder metallurgy, melt techniques and squeeze casting. However, powder metallurgy seems to be the preferred process due to more uniform dispersion of the reinforcement in the matrix. Also, better mechanical properties in MMCs can be attained by powder metallurgy process than liquid state processing [12]. Furthermore, this method has low processing temperature compared to melting techniques. In addition, interaction between matrix and the reinforcement phases is avoided due to low manufacturing temperature [13]. Another significant feature of powder metallurgy is the capability of producing near-netshape products [14]. To get good mechanical properties, good interfacial bonding between matrix and reinforcements must be achieved. If the interfacial bonding strength is weak, the interface debonding may occur leading to the microcrack initiation under low stress. Extrusion process homogenizes the particle distribution to some extent improving the interfacial bonding strength at matrix/particle interface, and thus it may achieve better properties [15].

However, fabrication of hybrid MMCs reinforced with hybrid particles of $\mathrm{Al}_{2} \mathrm{O}_{3}$ and $\mathrm{SiC}$ using powder metallurgy technique has not been considered yet. These hybrid composites were manufactured by stir casting [5, 16], liquid metal infiltration route [17], roll bonding [7] and squeeze casting method [10].

The aim of this study is to fabricate hybrid MMCs reinforced with $\mathrm{Al}_{2} \mathrm{O}_{3}$ and $\mathrm{SiC}$ in $\mathrm{Al}$ matrix by powder metallurgy. The effects of the weight fractions of $\mathrm{Al}_{2} \mathrm{O}_{3}$ and $\mathrm{SiC}$ on the tribological characteristics of the fabricated hybrid MMCs were investigated. Scanning electron microscopy (SEM) was used to study the interfacial bond between the reinforcement and the matrix. Further, the worn surface was examined.

\section{Experimental Work}

\subsection{Materials and Fabrication}

In the present study, commercial aluminum of $99.5 \%$ purity having spherical shape particles with an average size of $60 \mu \mathrm{m}$ was used as matrix material. SiC particles which have nonregular shapes with an average size of $300 \mu \mathrm{m}$ and spherical $\mathrm{Al}_{2} \mathrm{O}_{3}$ particles with an average size of $90 \mu \mathrm{m}$ were used as the reinforcements. SEM micrographs of $\mathrm{SiC}$ powder and $\mathrm{Al}_{2} \mathrm{O}_{3}$ particles are shown in Figs. 1 and 2. The MMCs were manufactured by powder metallurgy technique following the steps illustrated in Fig. 3. Blending is one of the crucial processes in powder metallurgy. In this process, $\mathrm{Al}$ matrix and $\mathrm{SiC}$ and $\mathrm{Al}_{2} \mathrm{O}_{3}$ reinforcements were thoroughly blended together at room temperature in order to reduce agglomeration and to obtain a uniform and homogeneous distribution. The blended mix is introduced into a mold cavity, which is lubricated with zinc stearate powder in order to minimize the frictions between die and punch, and also between billet and die and to prevent tears of the die and punch. The blended powders were coldcompacted to produce a weak cohesive mass called as green compact billets. The green billet has a cylindrical shape of $40 \mathrm{~mm}$ in diameter and $50 \mathrm{~mm}$ in long. The green billet was compacted with hydraulic press of 75 tons capacity by a pressure of $20 \mathrm{MPa}$. Then, the green billets were ejected from the die cavity, followed by a sintering process on the compacted billets. These billets were held for $8 \mathrm{~h}$ at $500{ }^{\circ} \mathrm{C}$, and then a hot extrusion process with an extrusion ratio of 16 was performed to produce $10-\mathrm{mm}$ diameter rods. This process aimed to attain a good distribution of $\mathrm{SiC}$ and $\mathrm{Al}_{2} \mathrm{O}_{3}$ particles in the $\mathrm{Al}$ matrix and reduce the voids in the final composite as well as to improve wetting between matrix and reinforcements. Furthermore, heating powders below the melting point allow solid-state diffusion and bond the particles together. Finally, the extruded rods were air-cooled to room temperature.

Table 1 shows different proportions of reinforcement materials used in fabricated hybrid MMCs. Due to the high hardness of $\mathrm{SiC}$ compared with $\mathrm{Al}_{2} \mathrm{O}_{3}$ [18-20], a specimen of $30 \mathrm{wt} \%$ of $\mathrm{SiC}$ was fabricated.

\subsection{Density and Porosity Measurements}

The density of the fabricated MMC samples was experimentally measured after each of cold compaction, sintering and extrusion processes. Using the well-known rule of mixture, the theoretical density $\left(\rho_{\text {th }}\right)$ of the MMC samples can be given by [8],

$\rho_{\text {th }}=\rho_{\text {sic }} \times V_{\text {sic }}+\rho_{\mathrm{Al}_{2} \mathrm{O}_{3}} \times V_{\mathrm{Al}_{2} \mathrm{O}_{3}}+\rho_{\mathrm{Al}} \times V_{\mathrm{Al}}$,

where $W$ and $\rho$ are the weight fraction and density of each component in the hybrid MMC, respectively.

The porosity in MMC samples was calculated from the difference between the theoretical density and the experimental density $\left(\rho_{\text {exp }}\right)$ as follows. 

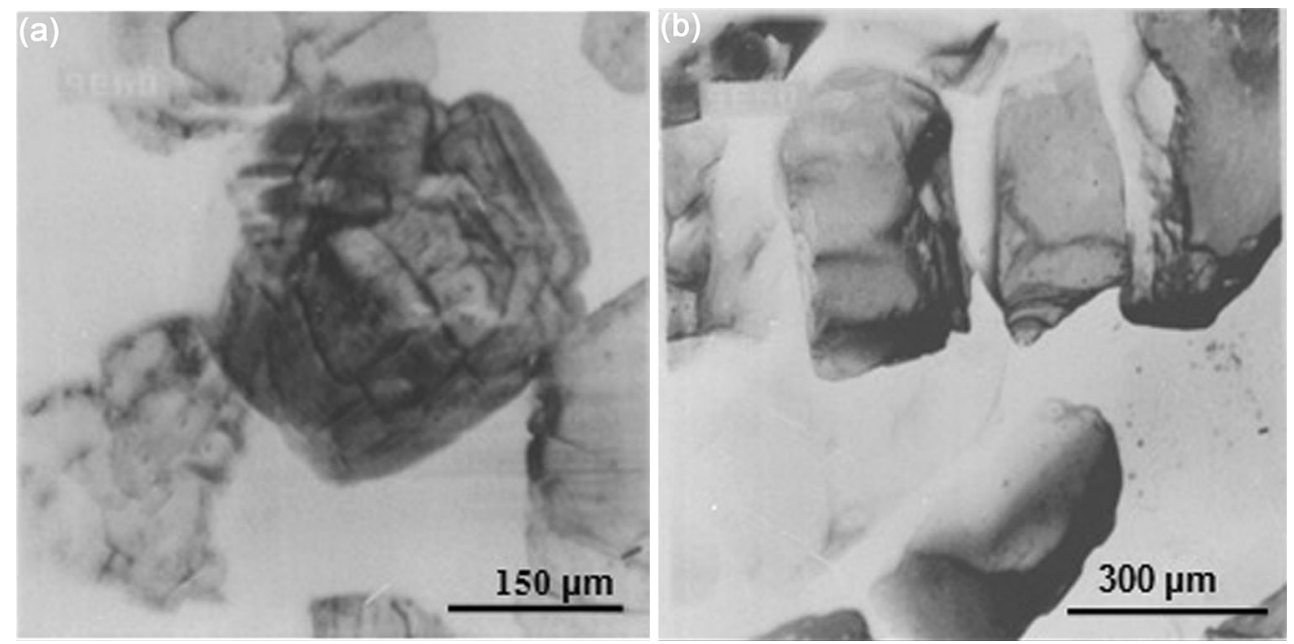

Fig. 1 SEM images of the aluminum oxide particles
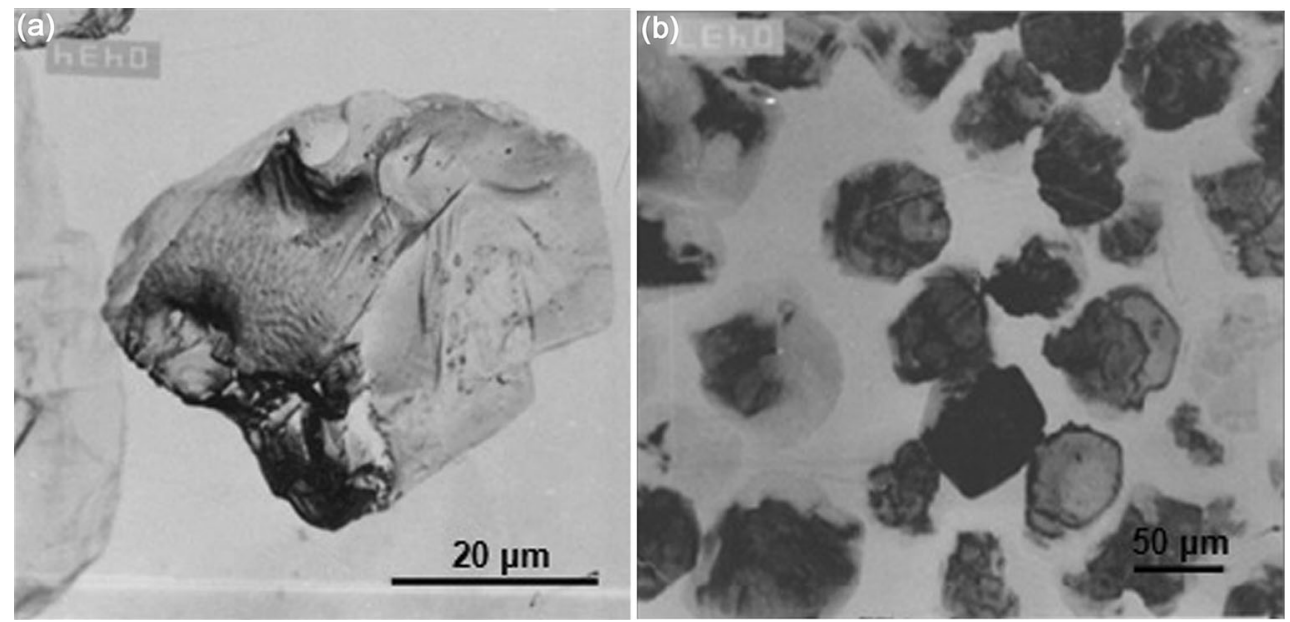

Fig. 2 SEM images of the aluminum oxide particles

Porosity $(\%)=100\left(\frac{\rho_{\text {th }}-\rho_{\text {exp }}}{\rho_{\text {th }}}\right)$.

\subsection{Microstructure and Tribological Characterization}

Microstructural investigations were conducted on the MMCs by using FEI Quanta 250 FEG with energy dispersive X-ray analysis (EDX).

The hardness measurement was taken by the Rockwell $\mathrm{C}$ hardness tester. Abrasive wear tests were carried out on the composite specimens using a pin-on-disk technique under normal loads of 5 and $10 \mathrm{~N}$ at sliding velocity of $1 \mathrm{~m} / \mathrm{s}$. In these tests, the tested specimens are loaded against a disk, which rotated at $250 \mathrm{rpm}$. The specimens were prepared for wear test as the surface is in contact with the disk. The disk carried an abrasive SiC paper of 120 Grit. The sliding distance was varied for each specimen. The pins were cleaned in acetone and dried prior to each weight measurement. Furthermore, the worn surfaces were studied.

\section{Results and Discussion}

\subsection{Density and Porosity for Hybrid Metal Matrix Composites}

The theoretical and experimental densities of the composites are represented in Fig. 4. The experimental density was measured after cold compaction, sintering and extrusion processes. As expected, the theoretical density is higher than the experimental one. It is noticed that the experimental density of hybrid composites is insignificantly affected by the cold compaction and sintering processes. The densification was not improved in sintered composites due to the porosity presented in aluminum or weak wettability in the interface of matrix and 


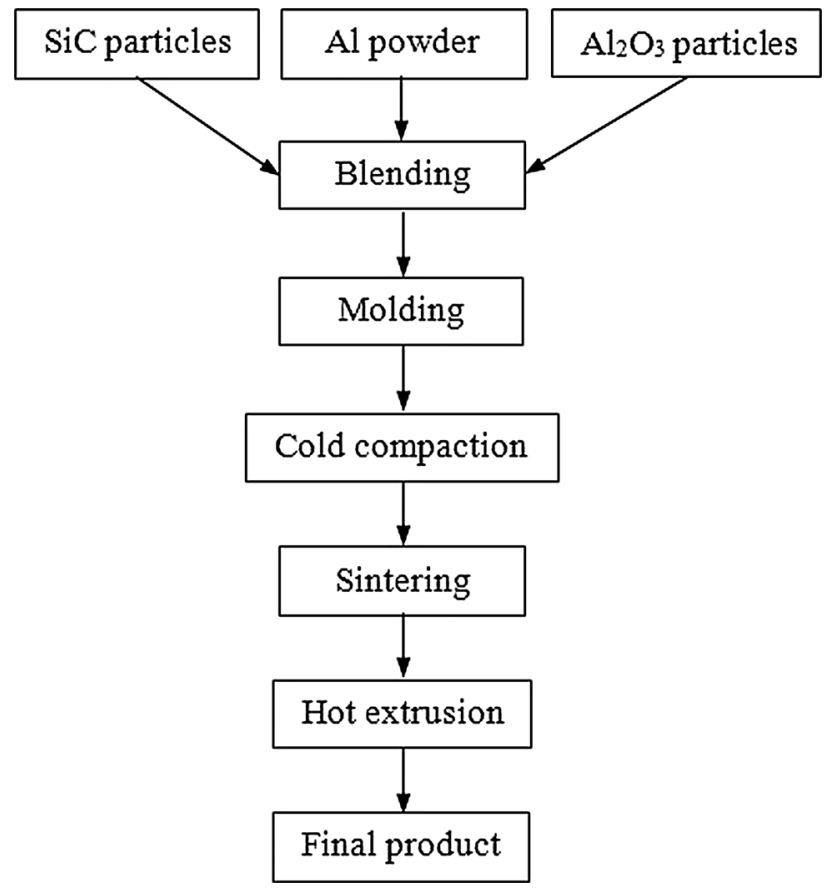

Fig. 3 Procedure of powder metallurgy used in processing the nonhybrid and hybrid MMCs

Table 1 Weight fraction of the particles in the hybrid metal matrix composites

\begin{tabular}{lcc}
\hline Sample & $\mathrm{SiC}(\mathrm{wt} \%)$ & $\mathrm{Al}_{2} \mathrm{O}_{3}(\mathrm{wt} \%)$ \\
\hline $5 \mathrm{SiC}^{2} \mathrm{Al}_{2} \mathrm{O}_{3}$ & 5 & 5 \\
$5 \mathrm{SiC} 25 \mathrm{Al}_{2} \mathrm{O}_{3}$ & 5 & 25 \\
$25 \mathrm{SiC} 5 \mathrm{Al}_{2} \mathrm{O}_{3}$ & 25 & 5 \\
$30 \mathrm{SiC}$ & 30 & 0 \\
Pure Al & 0 & 0 \\
\hline
\end{tabular}

reinforcement [8]. After extrusion process, density values increased for all specimens except for $5 \mathrm{SiC}_{2} 5 \mathrm{Al}_{2} \mathrm{O}_{3}$, and it is almost close to the density after sintering.
Consequently, the porosity after extrusion was decreased with different extents as depicted in Fig. 5. This is attributed to the elevated temperature induced during hot extrusion leading to reduction in the porosity and enhancement of densification as a result of forming a good bonding between $\mathrm{Al}$ matrix and reinforcements. The lowest porosity was observed with $30 \% \mathrm{SiC}$ and $25 \mathrm{SiC}_{5} \mathrm{Al}_{2} \mathrm{O}_{3}$ hybrid composite.

\subsection{Tribological Properties}

\subsubsection{Hardness Test}

Hardness of the composites was measured after extrusion. Measurements of Rockwell hardness of Grade C were taken on the plane perpendicular to the longitudinal axis of the extruded sample. Figure 6 clarifies that as the weight fraction of $\mathrm{SiC}$ particles increases, the hardness of MMCs increases over pure aluminum. The hardness of $5 \mathrm{SiC} 5 \mathrm{Al}_{2} \mathrm{O}_{3}$ was increased slightly over pure aluminum; however, hardness was increased significantly with $30 \mathrm{SiC}$ followed by $25 \mathrm{SiC} \mathrm{Al}_{2} \mathrm{O}_{3}$. This indicates that hardness of MMCs reinforced with $30 \mathrm{wt} \% \mathrm{SiC}$ is better than that of all hybrid MMCs. Also, keeping a constant content of $\mathrm{SiC}$, increasing the $\mathrm{Al}_{2} \mathrm{O}_{3}$ content has an insignificant effect on the hardness of the composite. Similar results were reported by Suresha and Sridhara [21], who found that hardness of aluminum reinforced with $10 \mathrm{wt} \% \mathrm{SiC}$ is greater than that of all hybrid (Al-SiC-graphite) MMCs. However, the improvement in hardness of MMCs with increasing content of $\mathrm{SiC}$ reinforcement can be attributed to the higher hardness of $\mathrm{SiC}$ reinforcement. During hardness test, as the indenter moves downward, it faces an increased resistance from the material. This phenomenon may be a result of the concentration of the $\mathrm{SiC}$ [22].

When the $\mathrm{Al}_{2} \mathrm{O}_{3}$ particles were increased in the composite at a constant value of $\mathrm{SiC}$ particles, the hardness of

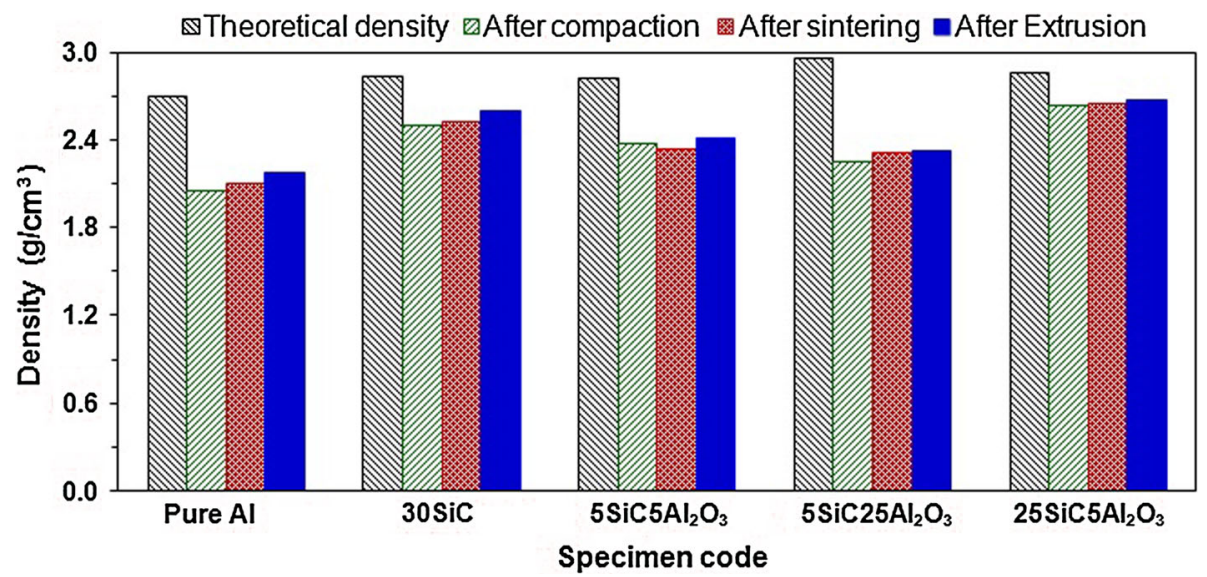

Fig. 4 Theoretical and experimental densities of the fabricated MMCs after cold compaction, sintering and extrusion processes 


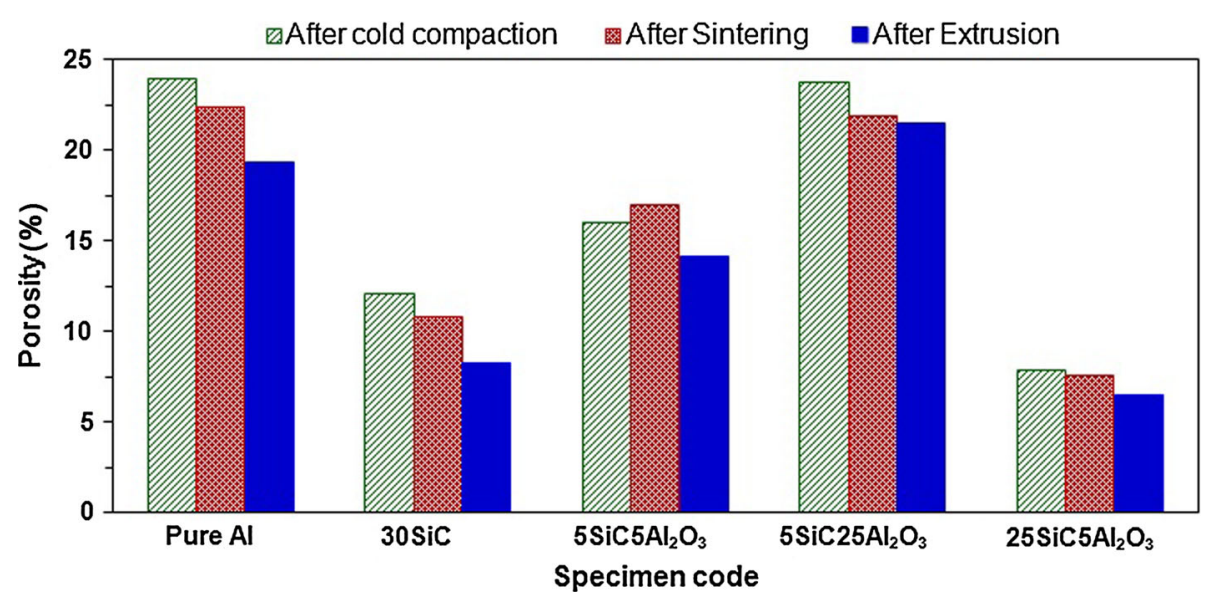

Fig. 5 Porosities of the fabricated MMCs after cold compaction, sintering and extrusion processes

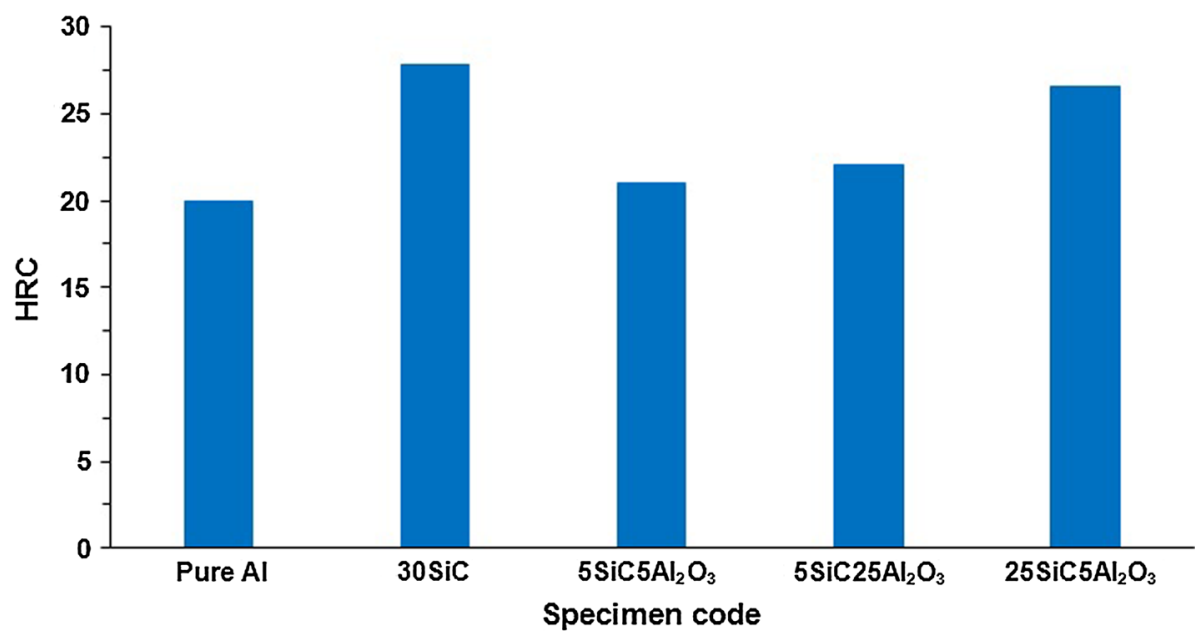

Fig. 6 Hardness of the fabricated pure aluminum and MMCs

the composite was slightly increased. For example, for the sample with $5 \mathrm{wt} \%$ of $\mathrm{SiC}$, the increase in $\mathrm{Al}_{2} \mathrm{O}_{3}$ from 5 to $25 \mathrm{wt} \%$ showed an increase in the Rockwell hardness of Grade C (HRC) by $4.7 \%$. On the other hand, a noticeable increase in the fabricated hybrid composite is achieved by increasing the amount of $\mathrm{SiC}$ particles keeping a constant content of $\mathrm{Al}_{2} \mathrm{O}_{3}$ particles; that is, for the sample with $5 \mathrm{wt} \%$ of $\mathrm{Al}_{2} \mathrm{O}_{3}$, the increase in $\mathrm{SiC}$ from 5 to $25 \mathrm{wt} \%$ showed an increase in the HRC by about $26.31 \%$. Therefore, it can be concluded that reinforced role of $\mathrm{SiC}$ particles in hardness of hybrid MMCs is much greater than that of $\mathrm{Al}_{2} \mathrm{O}_{3}$ particles. This is mainly attributed to the higher hardness of $\mathrm{SiC}$ over $\mathrm{Al}_{2} \mathrm{O}_{3}$ [18]. Similar finding was obtained by Hassan et al. [1] that the hardness of hybrid (Al-4 wt\% Mg/graphite/SiC) MMCs was increased by increasing the $\mathrm{SiC}$ particles at a constant value of graphite particles. Also, Jaswin et al. [23] concluded that the hardness of hybrid $\left(\mathrm{Al} / \mathrm{SiC} / \mathrm{B}_{4} \mathrm{C}\right) \mathrm{MMCs}$ increases with increasing the wt $\%$ of $\mathrm{SiC}$ rather than that of $\mathrm{B}_{4} \mathrm{C}$ particles.

\subsubsection{Wear Behavior}

Abrasive wear test was carried out on composites using a pin-on-disk technique. In this test, a thin layer of aluminum formed on the wear path as the aluminum matrix is very soft. In the initial stages of the test, the surface of the tested sample is fragmented due to polishing. At the beginning of the test, the contact areas of tested samples and abrasive disk are smaller than the total area of pin as the contact started in between them. The effective pressure on the contact area of the tested sample is much higher than that of the applied normal pressure. In such a way, this pressure will first break the surface of the sample. Due to the repeated loading action, the asperities of the matrix which represent the softer material surface are easily deformed and some of it is fractured due to surface fatigue. The asperities are thus deformed and removed leaving the tested sample surface nearly as smooth. The area of contact is thus increased with the increase in the sliding time, and the temperature of the tested pin will increase accordingly. The 
matrix will become softer, and the remaining asperities on the abrasive disk will plow the softer pin surface, and plastic shear flow would be accumulated with continuous repeated loading, and this represents the abrasive action and severe wear.

Figures 7 and 8 show the effect of sliding time on the weight loss of the MMCs with different weight fractions of $\mathrm{SiC}$ and $\mathrm{Al}_{2} \mathrm{O}_{3}$ particles at an applied normal load of 5 and $10 \mathrm{~N}$, respectively. It can be seen that the weight loss of aluminum matrix (pure $\mathrm{Al}$ ) is much greater than that of all fabricated MMCs. This indicates that addition of $\mathrm{Al}_{2} \mathrm{O}_{3}$ and/ or $\mathrm{SiC}$ particles improves the wear resistance of MMCs. For both normal load levels, the weight loss increases as the sliding time increases. As the weight fraction of reinforcement increases, the wear resistance of MMCs increases, i.e., sample with a total weight fraction of $10 \mathrm{wt} \%$ of reinforcement has wear resistance lower than that of $30 \mathrm{wt} \%$. This behavior is in agreement with Umanath et al. [5], who observed that wear resistance of $15 \mathrm{wt} \%$ reinforced hybrid MMCs is better than that with $5 \mathrm{wt} \%$. They reported that the wear resistance is almost the same for $5 \mathrm{wt} \%$ reinforced MMCs and the unreinforced alloy.

Also, it was found that increasing the weight fraction of $\mathrm{SiC}$ particles leads to the decrease in the weight loss of MMCs, i.e., wear resistance of $25 \mathrm{SiC} \mathrm{Al}_{2} \mathrm{O}_{3}$ is higher than that of $5 \mathrm{SiC}_{2} 5 \mathrm{Al}_{2} \mathrm{O}_{3}$. Hosking et al. [18], Gurcan and Baker [19] and Lee et al. [20] reported that $\mathrm{SiC}$ particles were more effective than $\mathrm{Al}_{2} \mathrm{O}_{3}$ particles for improving the wear resistance of reinforced composites due to the high hardness.

Comparing Figs. 7 and 8, it is found that as the applied normal load increases from 5 to $10 \mathrm{~N}$, the weight loss increases. Also, as the applied load increases, all fabricated
MMCs having a total weight fraction of $30 \mathrm{wt} \%$ were close to each other.

\subsubsection{Microstructural Analysis}

Distribution of the reinforcements in the hybrid MMC is one of the most important key factors influencing the properties of the composite. Therefore, careful microscopic examinations have been conducted on the cross section of the composite sample in order to examine the uniformity of distribution. The microscopic observation indicates that the distributions of $\mathrm{Al}_{2} \mathrm{O}_{3}$ and $\mathrm{SiC}$ particles in the cross section are uniform, as shown in Figs. 9 and 10. This uniform distribution of the reinforced particulates in the matrix yields an improved mechanical property of the fabricated MMCs, Altinkok and Coban [16]. Similarly, Altinkok and Coban [16] and Krishna and Xavior [24] also reported that the appropriate amount of uniformly distribution of reinforcement can improve mechanical properties of the composites.

The EDX analysis clarifies that $\mathrm{Al}_{2} \mathrm{O}_{3}$ and $\mathrm{SiC}$ particles are presented in the aluminum composites. The high pressure during the cold compaction process applied on the composite mixture by the punch is the main reason to break down most of the $\mathrm{SiC}$ particles and overcome its cohesive force as shown in Fig. 9. The microstructure investigation indicates the action of extrusion on the interface between matrix and reinforcement. Figures 9, 10 and 11 show that $\mathrm{Al}_{2} \mathrm{O}_{3}$ and $\mathrm{SiC}$ particles are completely surrounded by aluminum matrix. This in turn gives a good interfacial bonding between aluminum matrix and $\mathrm{Al}_{2} \mathrm{O}_{3}$ and $\mathrm{SiC}$ particles. It is well known that the wear resistance of MMCs depends on the bonding between the $\mathrm{Al}_{2} \mathrm{O}_{3}$ and $\mathrm{SiC}$

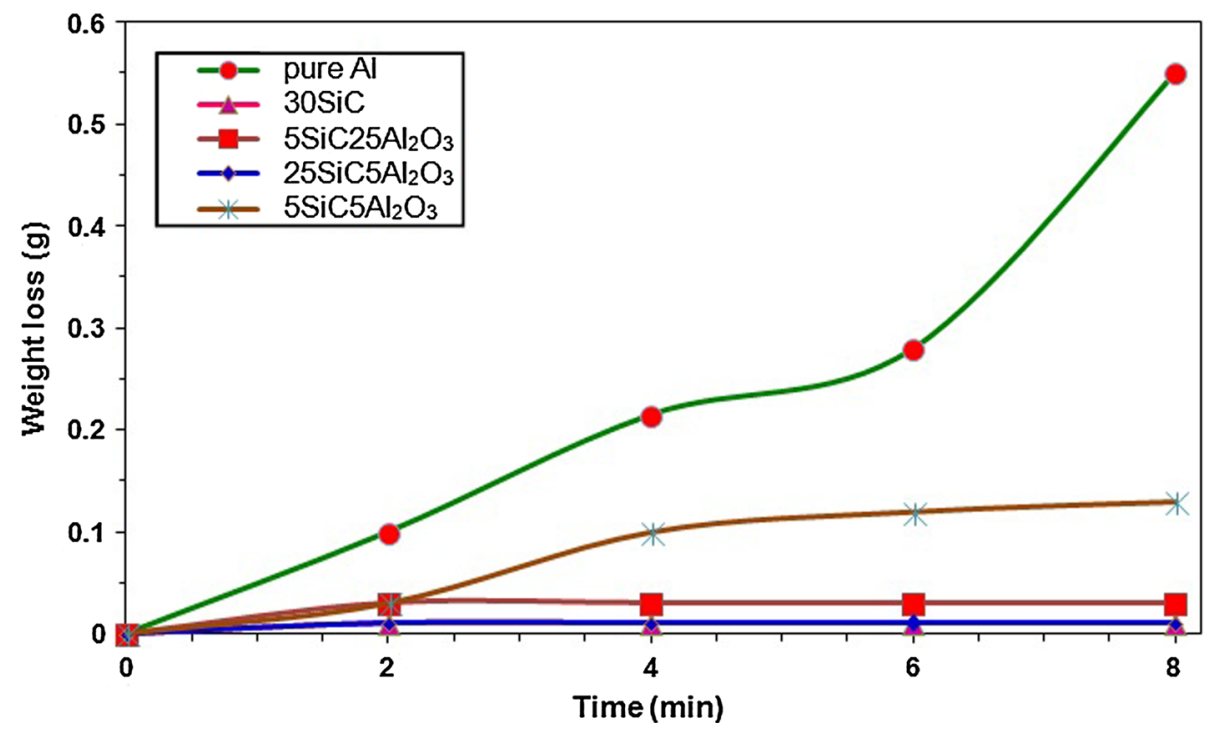

Fig. 7 Wear behaviors of aluminum and hybrid MMCs at load $5 \mathrm{~N}$ 


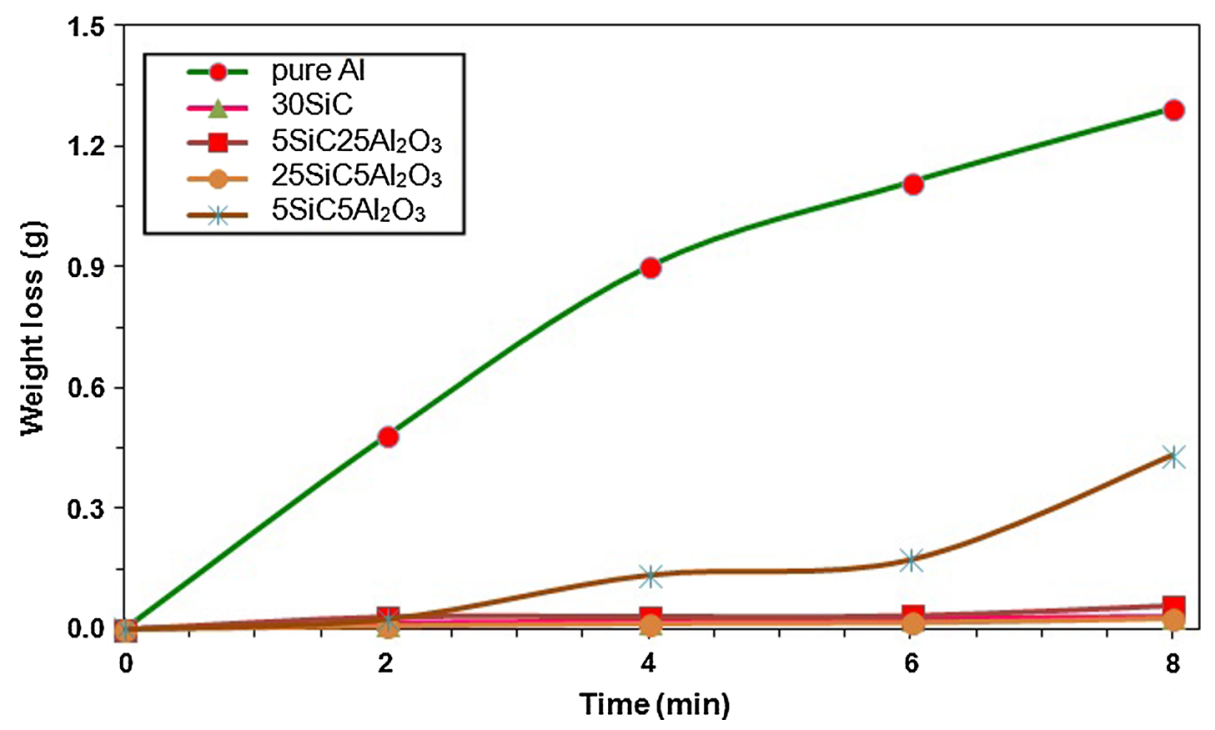

Fig. 8 Wear behaviors of aluminum and hybrid MMCs at load $10 \mathrm{~N}$

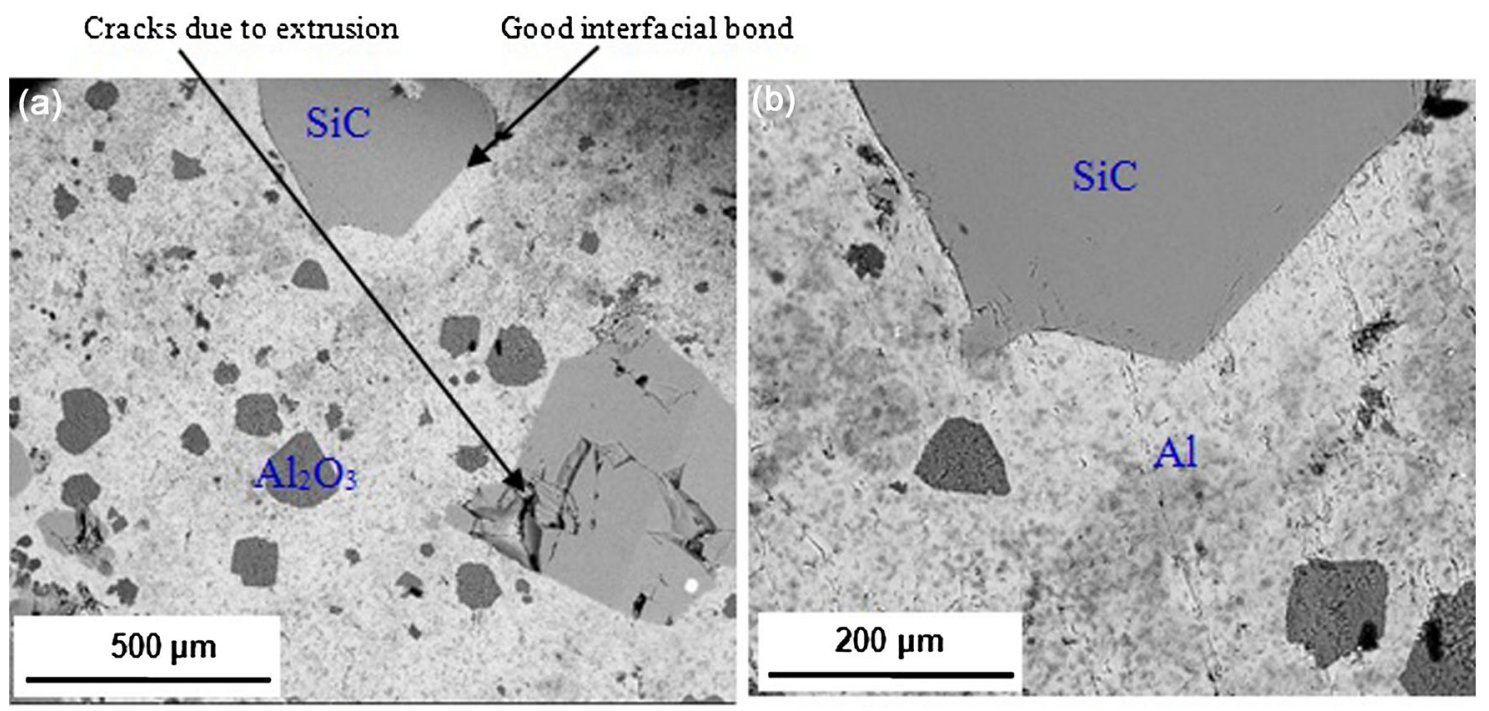

(c) $\overline{1.0 \mathrm{k}}$

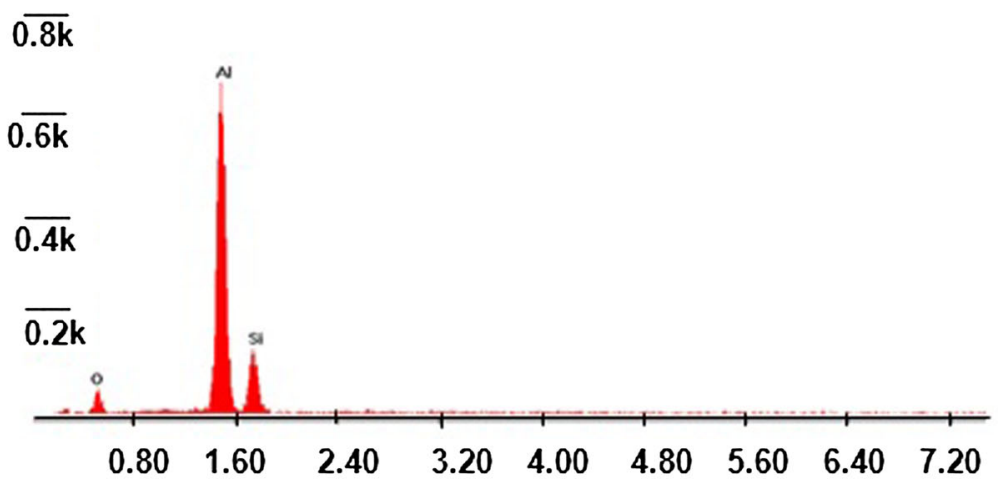

Fig. 9 SEM images a, b, EDX analysis $\mathbf{c}$ of hybrid $25 \mathrm{SiC} \mathrm{Al}_{2} \mathrm{O}_{3}$ composite 


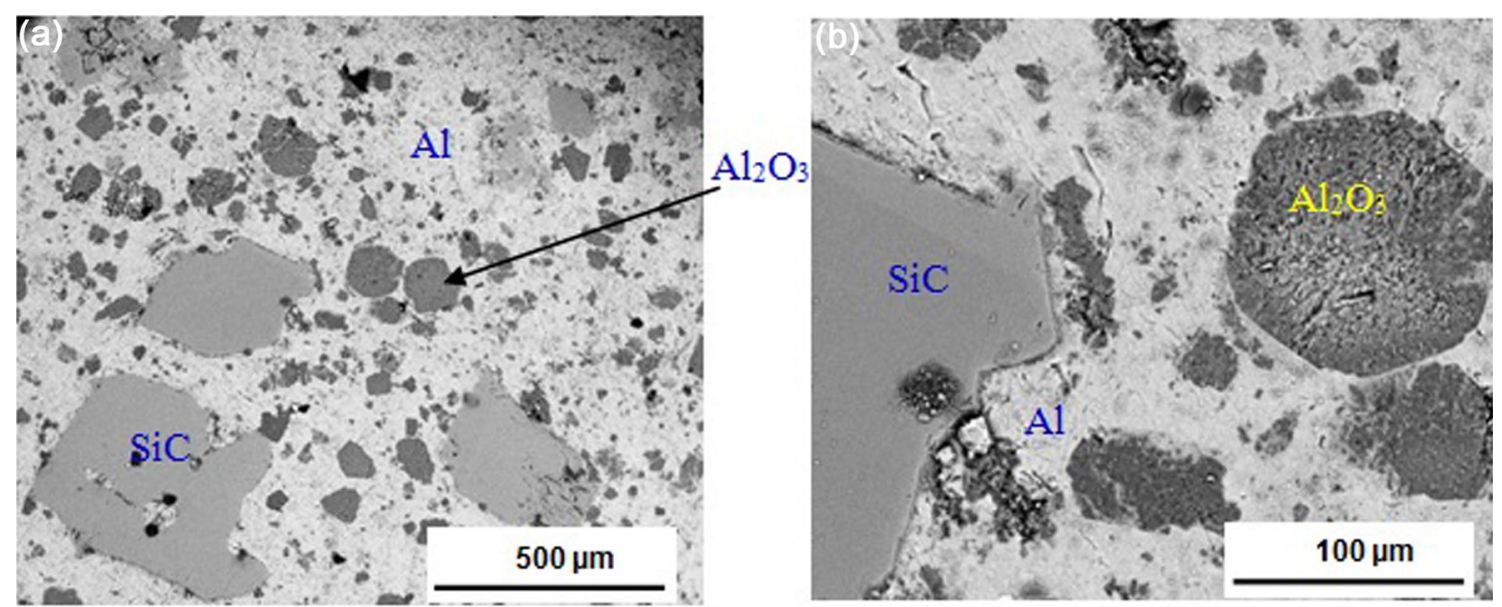

(c) $\overline{477}$

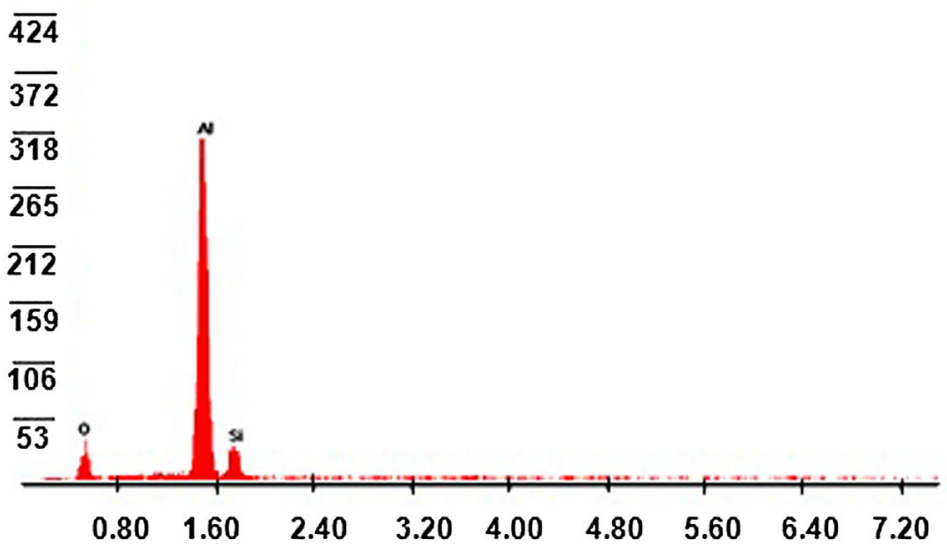

Fig. 10 SEM images a, b, EDX analysis c of hybrid $5 \mathrm{SiC}^{2} \mathrm{Al}_{2} \mathrm{O}_{3}$ composite

particles and metal matrix. A good bond between the particles and matrix prevents the particles from leaving the surface, and higher stress is required to separate the particles from the matrix and decrease the wear rate. A good interfacial bond between $\mathrm{SiC}$ particles and $\mathrm{Al}$ matrix is shown in Fig. 11. The obtained results show that by increasing the weight fraction of $\mathrm{SiC}$ or $\mathrm{Al}_{2} \mathrm{O}_{3}$ particles, hardness increases and the tribological properties and wear resistance of the fabricated MMCs are improved.

When the applied load increases, the weight loss increases. For both loads of 5 and $10 \mathrm{~N}$, the weight loss of hybrid $25 \mathrm{SiC}_{5} \mathrm{Al}_{2} \mathrm{O}_{3}$ composite is lower than that of the hybrid $5 \mathrm{SiC}_{5} \mathrm{Al}_{2} \mathrm{O}_{3}$ composite. The worn surfaces of specimens of hybrid $25 \mathrm{SiC} \mathrm{Al}_{2} \mathrm{O}_{3} \mathrm{MMC}$ corresponding to 5 and $10 \mathrm{~N}$ applied normal loads are shown in Fig. 12. However, Fig. 13 shows the worn surfaces of hybrid MMCs $\left(25 \mathrm{Si}_{5} \mathrm{Al}_{2} \mathrm{O}_{3}\right)$ at loads of 5 and $10 \mathrm{~N}$. It can be seen that the formation of plastic subsurface under light loads and sliding time, the plastic zones are limited and no interaction between these zones occurs leading to mild wear. As the load and sliding time increase, the plastic zones are enlarged Therefore, an increase in frictional forces, as a result of increasing the normal load, would in turn cause a temperature rise, a decrease in the hardness of the matrix surface and hence the wear is increased.

\section{Conclusion}

Hybrid MMCs reinforced with $\mathrm{Al}_{2} \mathrm{O}_{3}$ and $\mathrm{SiC}$ particles in $\mathrm{Al}$ matrix were fabricated using powder metallurgy technique. Tribological behavior of the fabricated hybrid MMCs was investigated. Results showed that extrusion process reduces largely porosity existed after cold compaction and sintering. Adding $\mathrm{Al}_{2} \mathrm{O}_{3}$ and $\mathrm{SiC}$ particles with different weight fractions improves hardness and wear resistance over pure aluminum. Increasing the weight fraction of $\mathrm{SiC}$ or $\mathrm{Al}_{2} \mathrm{O}_{3}$ reinforcement showed an increase in hardness and wear resistance. Also, $\mathrm{SiC}$ particles improve the tribological properties of the fabricated composite more than $\mathrm{Al}_{2} \mathrm{O}_{3}$ particles. The microscopic observation indicates that the $\mathrm{Al}_{2} \mathrm{O}_{3}$ and $\mathrm{SiC}$ particles are uniformly distributed with a better interface quality leading to the improvement of tribological properties of MMCs. 


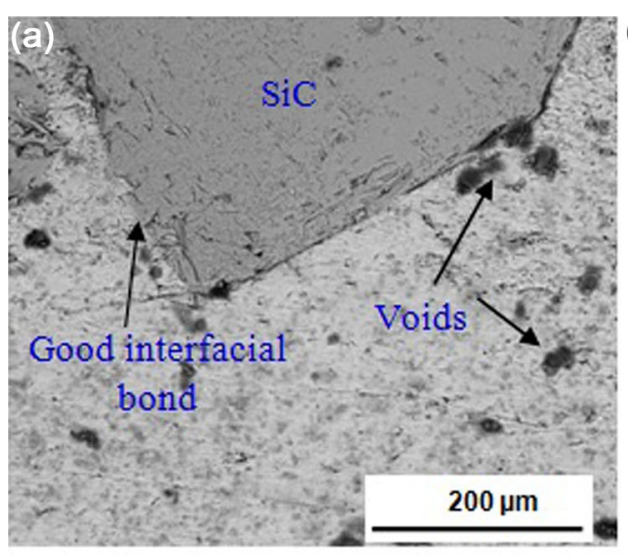

(b) $\overline{2.8 \mathrm{k}}$

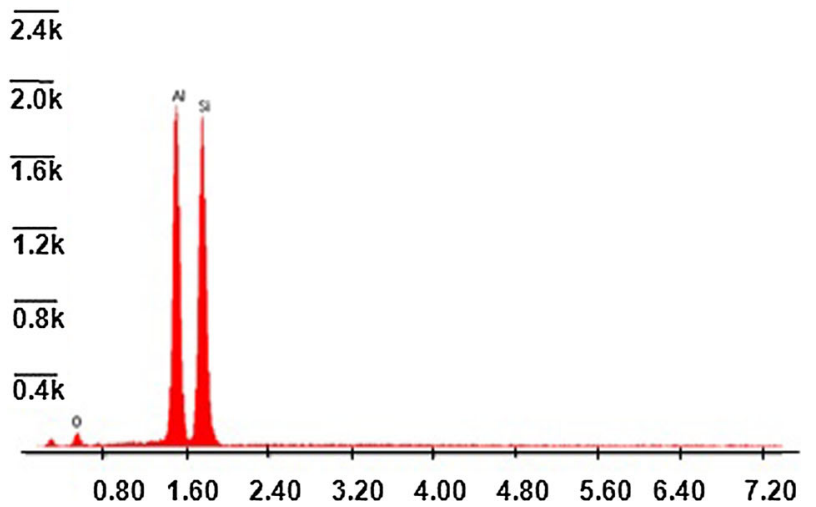

Fig. 11 SEM micrograph a, EDX analysis b of nonhybrid 30SiC composite
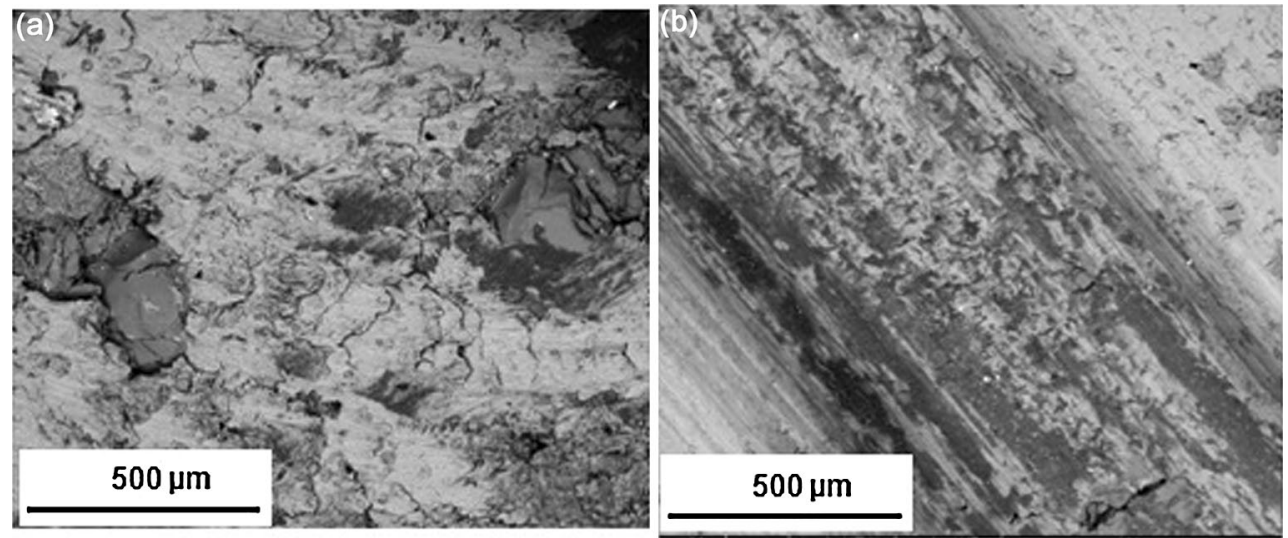

Fig. $12 \mathrm{SEM}$ images of worn surface of hybrid $\mathrm{MMCs}\left(5 \mathrm{SiC}^{2} \mathrm{Al}_{2} \mathrm{O}_{3}\right)$ at loads of $5 \mathbf{a}, 10 \mathrm{~N} \mathrm{~b}$
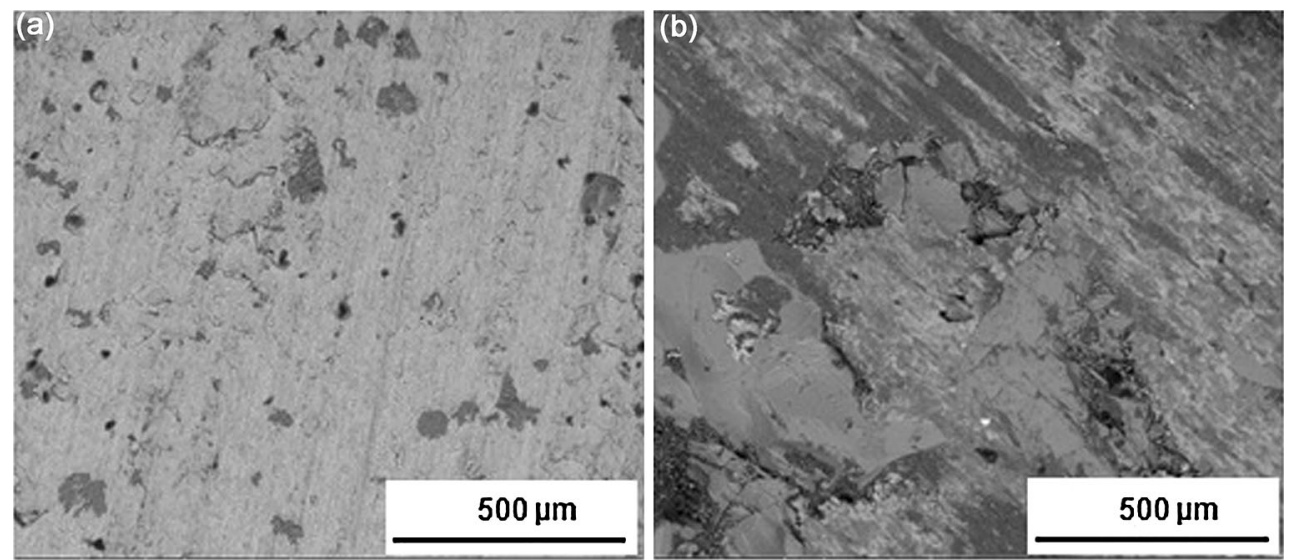

Fig. 13 SEM images of worn surface of hybrid MMCs $\left(25 \mathrm{Si}^{2} \mathrm{Al}_{2} \mathrm{O}_{3}\right)$ at loads of $5 \mathbf{a}, 10 \mathrm{~N} \mathrm{~b}$

\section{References}

[1] A.M. Hassan, G.M. Tashtoush, J.A. Al-Khalil, J. Compos. Mater. 41, 453 (2007)

[2] M. Rahimian, N. Parvin, N. Ehsani, Mater. Des. 32, 1031 (2011)

[3] H. Ahlatci, T. Kocer, E. Candan, H. Çimenoğlu, Tribol. Int. 39, $213(2006)$
[4] Ch. Yang, Ch. Huang, M. Reyes, L. Yan, X. Zhou, T. Xia, D. Zhang, Acta Metall. Sin. (Engl. Lett.) 28, 809 (2015)

[5] K. Umanath, K. Palanikumar, S. Selvamani, Compos. Part B Eng. 53, 159 (2013)

[6] M. Kok, J. Mater. Process. Technol. 161, 381 (2005)

[7] A. Ahmadi, M.R. Toroghinejad, A. Najafizadeh, Mater. Des. 53, 13 (2014) 
[8] C. Montalba, K. Ramam, D. Eskin, E. Ruiz-Navas, O. Prat, Mater. Des. 69, 213 (2015)

[9] A. Zeren, Ind. Lubr. Tribol. 67, 262 (2015)

[10] Y. Wang, A. Afsar, J. Jang, K. Han, J. Song, Wear 268, 863 (2010)

[11] X. Yang, J. Cheng, P. Song, Sh Wang, L. Yang, Y. Wang, K. Mao, Acta Metall. Sin. (Engl. Lett.) 26, 157 (2013)

[12] V. Bharath, M. Nagaral, V. Auradi, S. Kori, Procedia Mater. Sci. 6, 1658 (2014)

[13] J. Torralba, C. Da Costa, F. Velasco, J. Mater. Process. Technol. 133, 203 (2003)

[14] T. Varol, A. Canakci, S. Ozsahin, Acta Metall. Sin. (Engl. Lett.) 28, $182(2014)$
[15] J. Nie, J. Fan, Sh Zhang, Sh Wei, T. Zuo, M. Zili, Z. Xiang, Acta Metall. Sin. (Engl. Lett.) 27, 875 (2014)

[16] N. Altinkok, A. Coban, Int. J. Sci. Adv. Technol. 2, 78 (2012)

[17] N. Altinkok, J. Compos. Mater. 38, 1533 (2004)

[18] F. Hosking, F.F. Portillo, R. Wunderlin, R. Mehrabian, J. Mater. Sci. 17, 477 (1982)

[19] A. Gurcan, T. Baker, Wear 188, 185 (1995)

[20] C. Lee, Y. Kim, K. Han, T. Lim, J. Mater. Sci. 27, 793 (1992)

[21] S. Suresha, B. Sridhara, Compos. Sci. Technol. 70, 1652 (2010)

[22] Y. Shen, N. Chawla, Mater. Sci. Eng. A 297, 44 (2001)

[23] M. Jaswin, M. Prakash, K. Vignesh, Int. J. Adv. Eng. 1, 396 (2015)

[24] M. Krishnaa, A. Xavior, Procedia Eng. 97, 918 (2014) 